\title{
Neurotoxic effects of methylene chloride: Are they long lasting in humans?
}

\author{
Andrea A Lash, Charles E Becker, Yuen So, Michael Shore
}

\begin{abstract}
The neurotoxicity of methylene chloride (MC) is of special interest because of its acute effects on the central nervous system (CNS) and its metabolic conversion to carbon monoxide. A cohort study of retired airline mechanics was conducted to examine the hypothesis that long term exposure to $M C$ results in lasting effects on the CNS. Retirees were studied to eliminate effects of current occupational exposures. The total retiree population $(n=1758)$ was surveyed to identify mechanics who met specific occupational, demographic, and medical criteria. A group of eligible retirees having long term exposure to $M C$ and another group with low probability of exposure to solvents were given a comprehensive battery of physiological and psychological tests. The exposure groups were similar for all potential confounders that were measured. No statistically significant differences between groups were detected on outcome measures, although subtle differences in attention and memory were identified. Thus no firm evidence was found to support the hypothesis of lasting CNS effects in retired mechanics with long term exposure to MC.
\end{abstract}

Methylene chloride (MC) is a solvent widely used in industry as a paint thinner and stripper, a propellant for aerosols, and a cleaning agent. It is of special significance as a potential neurotoxin because of its direct effect as a central nervous system (CNS) depressant and also its metabolic conversion to a known neurotoxin, carbon monoxide. Case reports have associated MC poisoning with symptoms of

Center for Occupational and Environmental Health, University of California, San Francisco, USA

A A Lash, C E Becker

Department of Neurology, University of California, San Francisco, USA

Y So

California School of Professional Psychology M Shore dizziness, headaches, drowsiness, and memory loss. ${ }^{1-5}$ Experimental studies have documented that MC exposures of 200 to 300 parts per million (ppm) for four hours reduce vigilance and motor coordination. ${ }^{67}$ An epidemiological study conducted by Cherry $e t a l^{8}$ found that workers exposed to $M C$ in their job reported an unusually high number of neurological symptoms. These studies and reports support the hypothesis that exposure to $\mathrm{MC}$ can depress the CNS at least temporarily.

Data concerning neurotoxic effects that persist after exposure ceases are sparse. The case reports ${ }^{1-5}$ document little or no chronic CNS dysfunction, and they provide no evidence that exposure to $\mathrm{MC}$ was responsible for the few chronic symptoms that were seen. In experimental studies researchers stopped monitoring subjects when exposure to MC ended, thus losing the opportunity to study chronic effects. In the study of Cherry $e t a^{8}$ the increase in reported neurological symptoms may reflect only transient acute effects because the study participants were working with $\mathrm{MC}$ at the time of the survey. Also, the study may suffer from response bias and an inadequate comparison group of workers. In a follow up study that administered neurological and psychological tests to a sample of the original workers and to a matched comparison group the original finding was not supported. ${ }^{8}$

Our study was designed to test the hypothesis that long term exposure to comparatively low concentrations of MC produces lasting effects on the CNS. Of particular interest is the type of exposure that may be found in occupational settings-namely, repeated exposures that occur routinely over many years to MC concentrations within the range of federal and state guidelines. Interest in the CNS centres on reduced attention and memory, as these impairments have been reported not only for exposures to MC but also for exposures to other solvents. ${ }^{910}$ The design of the study differs from that of most retrospective studies of solvent exposures because the study groups were constructed specifically to meet particular design goals. It was our aim to eliminate current exposures to $\mathrm{MC}$ so that chronic effects could be studied, to maximise the exposure contrast and thus the possibility of observing effects, to control for potential confounding variables, and to examine 
sources of selection bias that could limit the generalisation of the research findings.

\section{Method \\ DESIGN}

The study employed an extreme groups design. Two groups of people were chosen that differed as much as possible in past solvent exposure but were as similar as possible in potential confounding variables. In an attempt to eliminate current workplace exposure, only retirees were studied. All study protocols were reviewed and approved by the Human Research Committee of the University of California, San Francisco.

\section{CONSTRUCTION OF OCCUPATIONAL STUDY GROUPS}

The study population consisted of retired airline mechanics who worked for a single airline and were members of one labour union. The labour union and airline provided us with access to the population and historical data about exposures to MC.

Retirees qualified for the field study on the basis of the jobs that they had held at the airline maintenance base. The research team met with representatives of the mechanics' labour union and the airline to identify target solvent exposed jobs having a high probability of routine exposure to $\mathrm{MC}$ and target comparison jobs having a low probability of any exposure to solvent. After the representatives identified these, the research team gathered information about the work practices and chemicals used in the jobs. Data were obtained by reviewing the airline company's records of all industrial hygiene assessments, by observing current work practices on visits to the workplace, and by interviewing long term employees who had held target jobs. From this information the list of target jobs was refined and reduced.

\section{Solvent exposed retirees}

To have been eligible to participate in the solvent exposed group, retirees had to have worked at least six years in one or more of 14 target jobs between the target years 1970 and 1984. The 14 mechanic jobs were located in the overhaul department of the maintenance base where aircraft were stripped of paint, repaired, rebuilt, and repainted. During the interval from 1970 to 1984 , mechanics in the overhaul department routinely employed MC based paint stripper. They poured the stripper from hoses onto aircraft parked inside a hangar or maintenance dock while other mechanics worked in, under, and on the aircraft. The 14 target jobs were those of the paint strippers and the other mechanics who worked in and around the aircraft during the stripping process. Although the use of MC before 1970 was not formally documented, representatives of the airline and the labour union reported that paint strippers containing $M C$ had been used continuously in this department since the early 1960s. After 1984, the company's policy changed and, since then, mechanics who are not directly concerned with the application of the paint stripper must vacate the hanger during the stripping process. We established six years as the minimum duration for eligibility so that we could maximise the exposure contrast and still obtain a reasonable number of eligible retirees.

Table 1 summarises all the industrial hygiene data concerning exposures to $M C$ that were gathered in the overhaul department by the company. The measurements were taken between 1974 and 1986, a 12 year interval towards the end of the retirees' tenures. Exposures of the mechanics to MC in target jobs ranged from low concentrations to as much as $800 \mathrm{ppm}$. On average mechanics who were not stripping paint experienced exposures of $100 \mathrm{ppm}$, the current permissible exposure limit in California. Mechanics who were responsible for painting and stripping the aircraft experienced exposures of $225 \mathrm{ppm}$ on average.

\section{Comparison retirees}

The comparison group of retired mechanics had held jobs at the maintenance base that corporate and

Table 1 Methylene chloride exposure

\begin{tabular}{|c|c|c|c|c|c|c|}
\hline \multirow[b]{2}{*}{ Sample type } & \multirow[b]{2}{*}{ Years } & \multirow[b]{2}{*}{ No of samples } & \multirow{2}{*}{$\begin{array}{l}\text { Sample } \\
\text { Duration (min) }\end{array}$} & \multicolumn{3}{|c|}{ Time weighted average (ppm) } \\
\hline & & & & Mean & Lowest & Highest \\
\hline Painter breathing zone & $\begin{array}{c}1975-1977 \\
1986\end{array}$ & 8 & $>60$ & 236 & 42 & 660 \\
\hline Painter breathing zone & $\begin{array}{c}1974-1975 \\
1982\end{array}$ & 16 & $<35$ & 219 & 4 & 450 \\
\hline $\begin{array}{l}\text { Mechanic breathing zone } \\
\text { Mechanic breathing zone } \\
\text { Area: inside aircraft } \\
\text { Area: inside aircraft } \\
\text { Area: inside cargo pit } \\
\text { Area: outside aircraft } \\
\text { Area: outside aircraft }\end{array}$ & $\begin{array}{l}1986 \\
1986 \\
1975-1977 \\
1986 \\
1986 \\
1986 \\
1986\end{array}$ & $\begin{array}{r}12 \\
7 \\
26 \\
15 \\
11 \\
33 \\
27\end{array}$ & $\begin{array}{l}>120 \\
<120 \\
<45 \\
>60 \\
>60 \\
>120 \\
<120\end{array}$ & $\begin{array}{r}82 \\
105 \\
102 \\
97 \\
117 \\
101 \\
105\end{array}$ & $\begin{array}{r}10 \\
32 \\
0 \\
20 \\
41 \\
11 \\
8\end{array}$ & $\begin{array}{l}247 \\
217 \\
430 \\
483 \\
483 \\
826 \\
395\end{array}$ \\
\hline
\end{tabular}


labour represenatives identified as having a low probability of exposure to solvents. Ten target comparison jobs were located in the jet shop where jet engines are dismantled and reassembled, or in line maintenance, where aircraft receive routine maintenance. The company had no industrial hygiene data for the comparison jobs. By study of current practices and interviews with long term employees, however, the research team confirmed that little solvent was used in these or neighbouring jobs. Subjects were excluded from the comparison group if they had worked for more than two years in any other jobs on the airline maintenance base.

\section{Medical and demographic criteria}

As well as meeting the occupational criteria, subjects had to meet specific medical and demographic criteria. We excluded from the study any subjects known at recruitment to have had a disorder of the CNS, such as a seizure or stroke; people who were diagnosed to have alcoholism by a physician or who reported a lifetime consumption of alcohol that exceeded $1000 \mathrm{~kg}$; women, because they comprised less than $5 \%$ of the population of mechanics; and retirees younger than 55 or older than 75 .

\section{SUBJECT IDENTIFICATION AND RECRUITMENT}

Subject identification and recruitment had three stages of data collection. The first consisted of sending a questionnaire to the complete population of retired members of the airline mechanics' union.
Sixty per cent of the 1758 retirees responded (fig 1 ). According to their responses, 259 retirees met the medical, demographic, and general employment criteria. The second stage of data collection was a telephone survey designed to gather detailed information on employment. Based on interview responses, 91 people were qualified to participate in the field study; roughly half of them were exposed subjects. The final stage was recruitment of subjects. The qualified retirees received an information packet about the field study that contained an invitation to participate followed by a telephone call from a member of the research team.

\section{Exposure history of study groups}

Figure 2 displays the work history of the 25 retirees who comprised the solvent exposed group for the field study. On average, the retirees worked in the solvent exposed jobs for 11.6 of the target years and for 23.8 years in all. For most, employment in these jobs was continuous. Retirees in the comparison group worked only in comparison jobs during their tenure with the airlines with the possible exception of two years in some other assignment.

\section{Bias substudies}

Two substudies were conducted to assess potential sources of bias that would limit the generalisation of the research findings. The first examined nonresponse bias in the questionnaire survey. Telephone interviews were attempted with a random $30 \%$
1 Surveyed by mail $(n=1758$ )

Survey respondents $(n=1040)$

2

Telephone survey population (Met job and other criteria) $(n=259)$

Completed phone interviews $(n=229$ )

Met specific job criteria $(n=91)$

Recruited and tested $(n=46)$

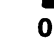

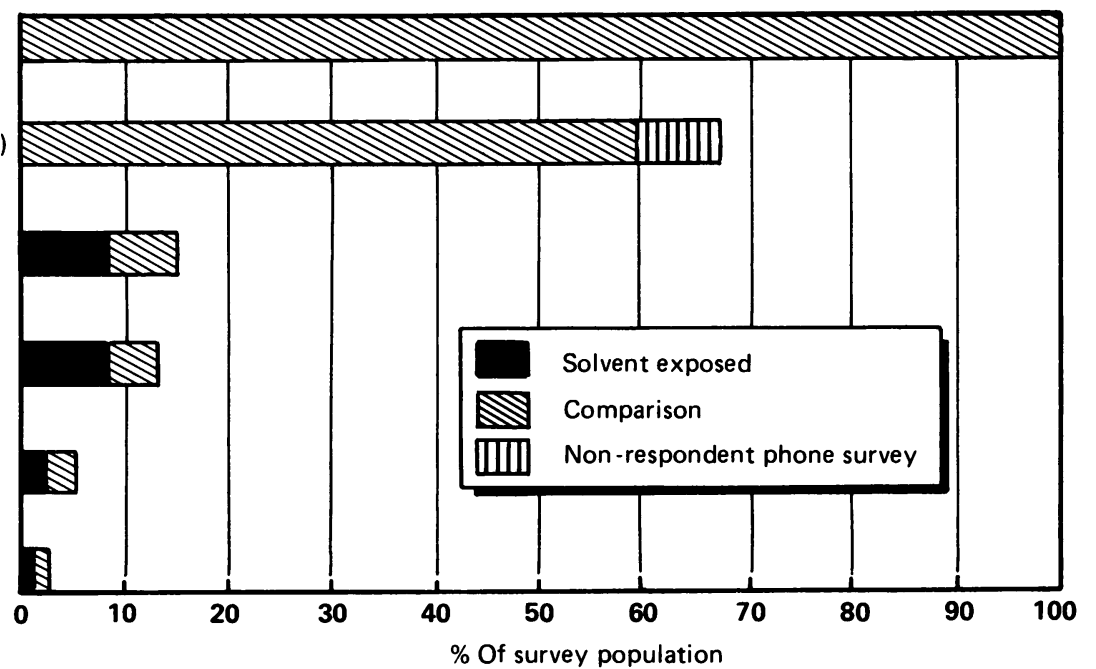

Figure 1 Identification and recruitment of study participants. 


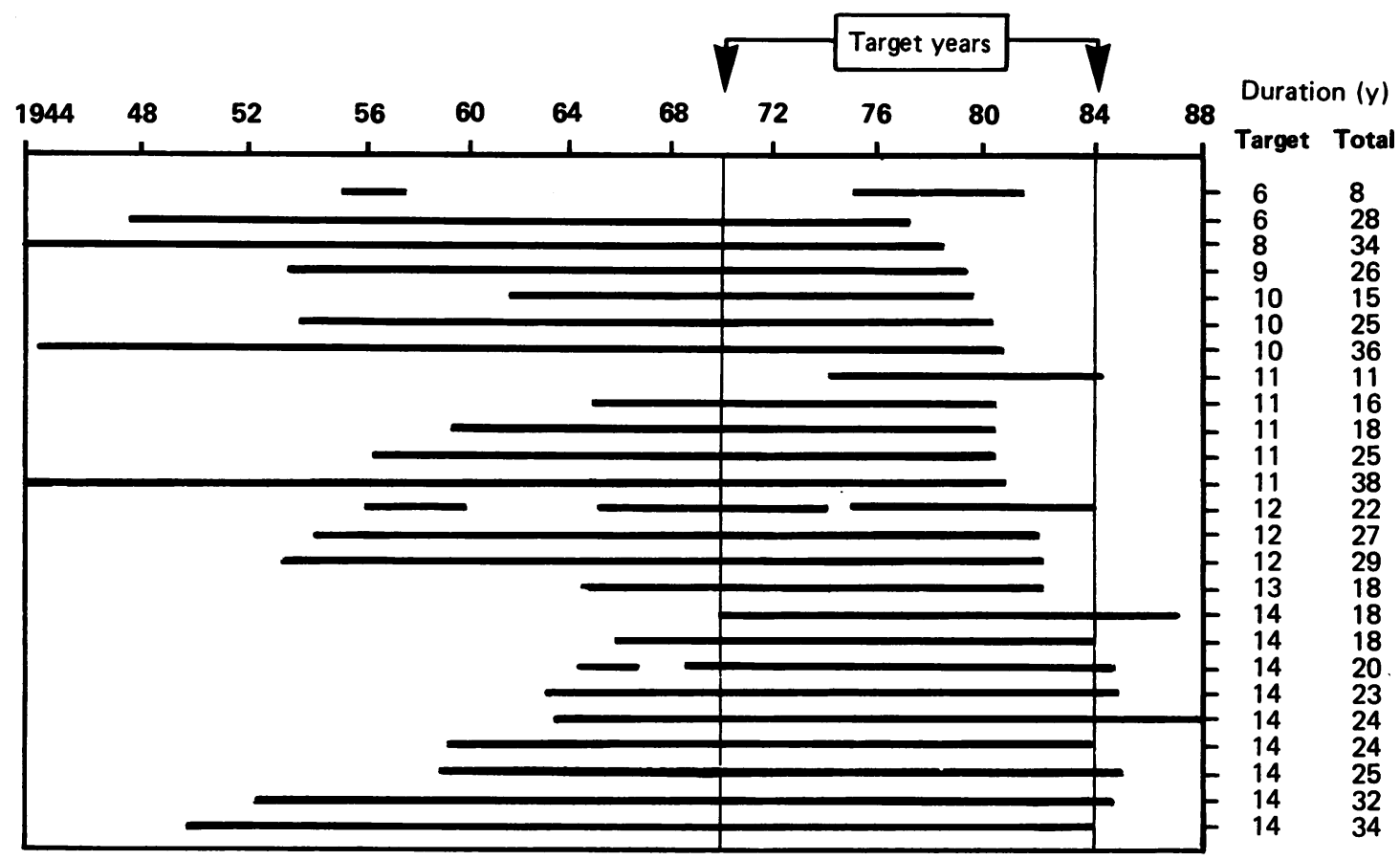

Figure 2 Years employed in solvent exposed jobs for 25 retirees.

sample of non-respondents $(n=213)$ and information was obtained from 97 retirees $(46 \%$ of the sample). The remaining retirees in the sample were not listed in telephone directories $(47 \%)$ or did not answer their phone in three attempts $(7 \%)$. Sixty five retirees $(67 \%$ of those contacted) completed the interview. Interviews were not obtained for the remaining retirees because they refused $(16 \%)$, were ill $(7 \%)$, were dead $(7 \%)$, or had not worked for the target airline company (2\%). The responses obtained represent about $10 \%$ of the non-respondent population.

Table 2 contrasts demographic and health characteristics of the retirees who responded to the mail survey with those who completed the telephone survey. The groups did not differ in the percentage speaking English at home, the percentage who were men, the percentage diagnosed with each of eight

Table 2 Comparison of questionnaire survey: respondents and non-respondents

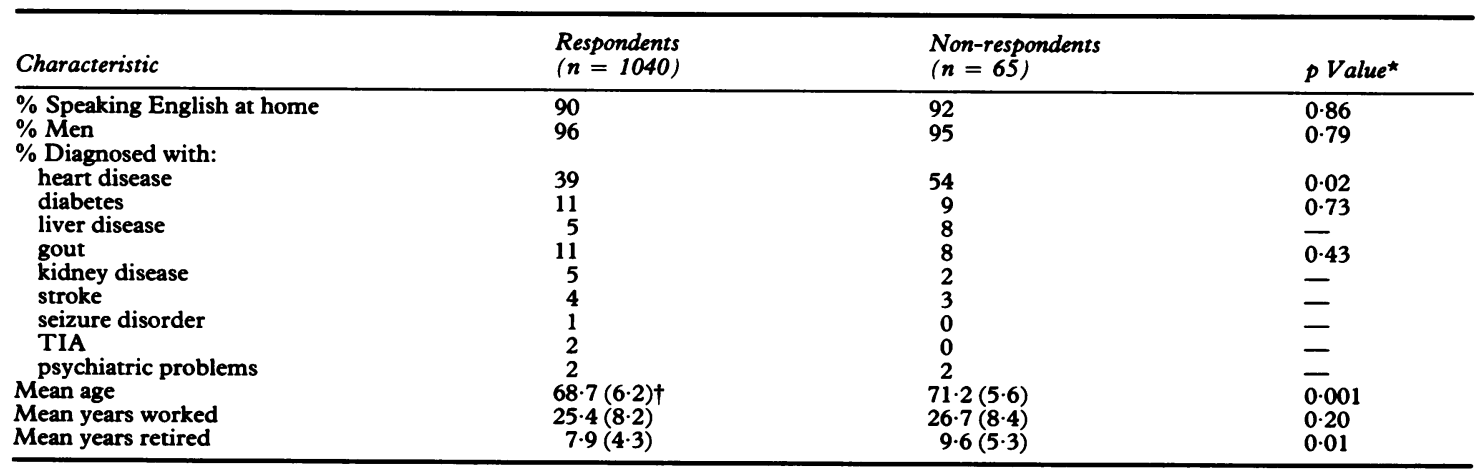

Information for survey non-respondents was obtained through telephone interviews.

${ }^{\star} \chi^{2}$ tests were employed for discrete variables and two way $t$-tests for continuous variables. When the frequency for a discrete value was less than 5 , the $\chi^{2}$ test was not completed.

$\dagger$ Numbers in parenthesis are standard deviations. 
diseases, or in tenure at the airline. Questionnaire non-respondents were older on average by 2.5 years $(t=3.25, p \leq 0.001)$, had been retired 1.7 years longer on average $(t=2.52, p \leq 0.02)$, and a greater percentage of them had been diagnosed with heart disease $\left(\chi^{2}=5 \cdot 2, \mathrm{df}=1, \mathrm{p} \leq 0.03\right)$. Thus the group of retirees who responded to the survey (including solvent exposed, comparison, and ineligible retirees) may have been younger than the population as a whole. With the exception of heart disease, respondents and non-respondents reported a similar health state.

The second substudy compared retirees who participated in the field study with those who were eligible but who did not. Retirees eligible for the solvent exposed group who did not participate were similar to the participants in all variables measured (table 3). For the comparison group, the percentage of people having gout was greater for participants than non-participants; no other significant differences in demographic or health characteristics were noted.

\section{MEASURES}

Five categories of variables were assessed in the field study of eligible retirees: demographic and potential confounders, health symptoms, and physiological, psychophysical, and psychological variables.

\section{Demographic and confounding variables}

Retirees provided their age and education level in their response to the mail questionnaire. The potential confounders of verbal ability, depression, and anxiety were measured at the field site by the vocabulary test of the Wechsler adult intelligence scale $^{11}$ the Beck depression inventory, ${ }^{12}$ and the selfevaluation questionnaire. ${ }^{13}$ Using a standardised questionnaire a physician interviewed each subject to obtain an estimate of the total amount of alcohol the retiree had consumed over the course of his lifetime.

\section{Health symptoms}

The questionnaire sent to all airline mechanics asked people to report on a five point scale how seriously they had experienced each of 33 symptoms over the past year; many of the symptoms related to disorders of the CNS.

\section{Physiological variables}

Three types of physiological characteristics were assessed at the field site-namely, special senses, grip strength, and P300 event related potential. The PMcarbinol odour test provided the measure of the sense of smell. This test estimates a threshold limit value for odour on a normalised scale in units, known as decismels, that are a function of the concentration of the odourous chemical in the stimuli. ${ }^{14}$ Colour vision was assessed with the Lanthony 15 hue, a colour arrangement task. The quantitative measure derived from this test indicates the degree of confusion or disorder in a subject's arrangement of the stimulus colours. ${ }^{15}$ Using a hand dynomometer, grip strength was measured twice for each hand and the four measurements were averaged.

For the $\mathrm{P} 300$ event related potential, evoked responses were obtained to bi-aural presentation of a

Table 3 Characteristics of participant and qualified non-participant groups

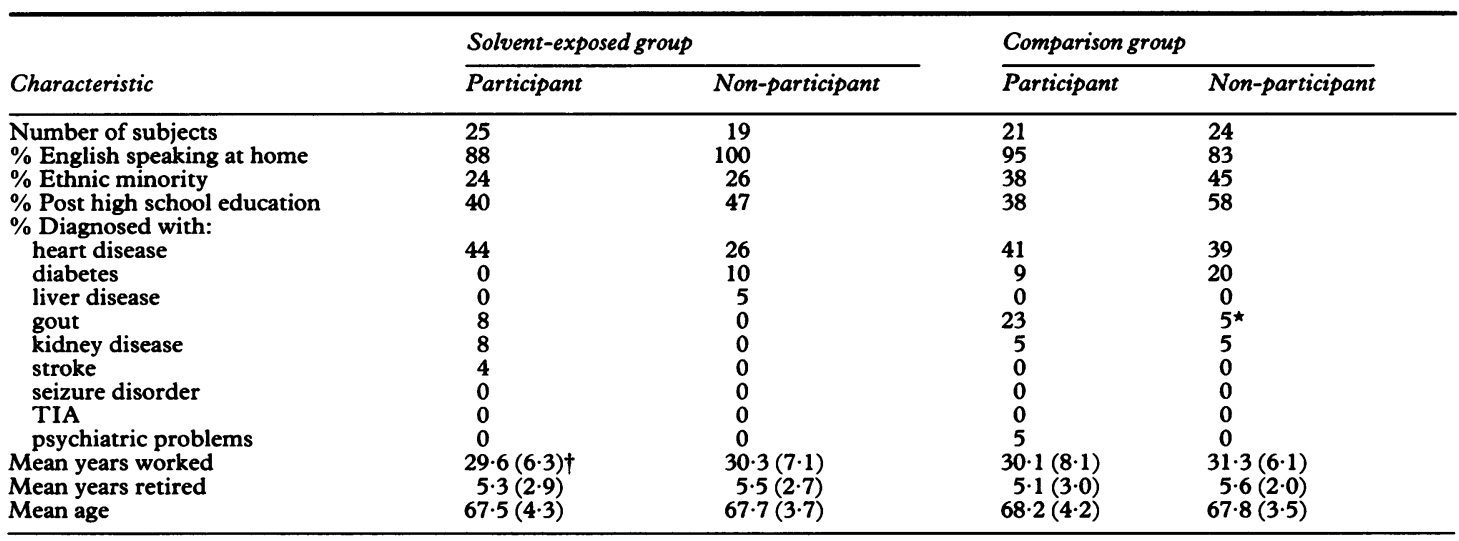

Differences between participant and non-participant groups were assessed separately for eligible solvent exposed and comparison retirees. Also, the participant solvent exposed and comparison groups were compared. $\chi^{2}$ Tests were employed for discrete variables and $t$ tests for continuous variables.

${ }^{\star} \mathrm{p} \leq 0.05$ for participant $v$ non-participant retirees in the comparison group.

$\dagger$ Numbers in parentheses are standard deviations. 
random sequence of 1000 and $2000 \mathrm{~Hz}$ tones $(70 \mathrm{db} \mathrm{nHL}, 80 \mathrm{~ms}$ duration, at a rate of $1 \mathrm{~Hz}) .{ }^{16}$ The $1000 \mathrm{~Hz}$ tone (frequent) occurred in $85 \%$ of the trials and the $2000 \mathrm{~Hz}$ tone (rare) in the remaining $15 \%$. Subjects were instructed to keep a mental count of the total number of rare tones. An electroencephalogram (ECG) was recorded at $C_{2}$ referred to linked mastoid (10-20 system) using a bandpass of 1 to $30 \mathrm{~Hz}$, and responses to the two tones were averaged separately. The latency of the $\mathrm{P} 300$ potential was measured to the point of intersection of extrapolating lines from the ascending and descending slopes. The amplitude was defined as the potential difference between the $\mathrm{P} 300$ peak and the preceding negative peak.

\section{Psychophysical variables}

Reaction time and motor speed were examined at the field site using the neurobehavioural evaluation system (NES) version $3 \cdot 2 .{ }^{17}$ Four variables were measured: finger tapping, simple reaction time, choice reaction time, and complex choice reaction time, the slope in the Sternberg subtest of the NES. This last variable is an estimate of the time a person requires for cognitive processing of a single visual stimuli in a choice reaction time task.

\section{Psychological variables}

Six psychological variables were examined at the field site, most by more than one test.

Short term visual memory was assessed by the figural memory test, the visual paired associates test, and the visual reproduction test of the Wechsler memory scale revised. ${ }^{18}$ For a retention measure of visual memory, the delayed versions of the visual reproductions and visual paired associates were given. Short term verbal memory was assessed by employing the verbal paired associates and the logical memory tasks of the Wechsler memory scale revised and the selective reminding task. ${ }^{19}$ The retention measures of verbal memory were the delayed versions of these three verbal tests. Attention was assessed by six tests: digit span and digit symbol from the Wechsler adult intelligence scale revised, ${ }^{11}$ the paced auditory serial addition test (PASAT), ${ }^{20}$ the Stroop test, ${ }^{21}$ trailmaking, ${ }^{22}$ and a cancellation task named Ruff's twos and sevens. ${ }^{23}$ Spatial ability, measured by the mental rotation test, ${ }^{24}$ was also included in the battery of psychological tests.

\section{DATA COLLECTION AND ANALYSIS}

Data collection

The retirees completed the battery of tests individually by working through seven test stations at the field site. At each station retirees worked with a trained examiner who did not know the retirees' exposure state. The full battery required four to five hours to complete. The team of examiners consisted of physicians, nurses, psychologists, and technicians who were specially trained in the areas they tested.

\section{Data processing}

Interscorer reliability was examined for all psychological tests by having two examiners score the responses from a random sample of 20 retirees. Systematic scoring differences were resolved and corrected in the full set of data. All data were entered into computer files and the accuracy of the files was verified by comparing two independent entries of each file. Summary scores for colour vision, depression, anxiety, alcohol intake, motor speed, and reaction time were derived by computer analysis of the responses to test items.

\section{Statistical analysis}

The dependent variables, all of which are continuous, were analysed using $t$ tests. Composite scores were created for memory and attention tests by totalling the scores of individual tests once each test was standardised on the pooled group of subjects. For the sample sizes of this study, the $t$ test has adequate power to detect large effects. The power of the two sided $t$ test is $0.75,0.84$, and 0.91 to detect effect sizes of $0.8,0.9$, and 1.0 respectively. ${ }^{25}$ Even though the sample sizes are relatively small, the current study has sufficient power to detect large differences between the study populations.

\section{Results}

\section{Demographic and potential confounding variables}

The solvent exposed and comparison groups did not differ significantly in measures of demographic and potential confounding variables (tables 3 and 4). On average, study participants in both groups were around 68 years of age, had worked for the airline for about 30 years, and had been retired for about five years.

\section{Dependent variables}

Table 4 and fig 3 presents the statistical results. To facilitate comparisons across variables, fig 3 provides estimates of the effect size,

$$
\left(\overline{\mathbf{X}}_{\mathrm{c}}-\overline{\mathbf{X}}_{\mathrm{c}}\right) / \mathbf{s}_{\mathrm{p}}
$$

where $\bar{X}_{c}$ is the mean value of the solvent exposed group, $\bar{X}_{c}$ is the mean value of the comparison group, and $s_{p}$ is the pooled, within group standard deviation.

As noted in the tables, lower scores indicate better performance for some variables. For those variables, 
Table 4 Comparison of study groups on potentially confounding variables and health symptoms

\begin{tabular}{|c|c|c|c|}
\hline Variable & $\begin{array}{l}\text { Exposed }(n=25) \\
(\text { mean }(S D))\end{array}$ & $\begin{array}{l}\text { Control }(n=21) \\
(\text { mean }(S D))\end{array}$ & p Value \\
\hline $\begin{array}{l}\text { Potential confounders: } \\
\text { Alcohol consumed }(\mathrm{Kg}) \\
\text { Verbal ability } \\
\text { Anxiety } \\
\text { Depression }\end{array}$ & $\begin{array}{r}177 \cdot 3(184 \cdot 27) \\
47 \cdot 6(10 \cdot 42) \\
32 \cdot 7\left(\begin{array}{r}7 \cdot 46) \\
6 \cdot 0(3 \cdot 47)\end{array}\right.\end{array}$ & 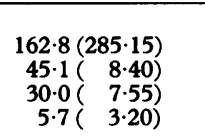 & $\begin{array}{l}0 \cdot 82 \\
0 \cdot 39 \\
0 \cdot 22 \\
0 \cdot 80\end{array}$ \\
\hline $\begin{array}{l}\text { Health symptoms: } \\
\text { No reported } \\
\text { Severity }\end{array}$ & 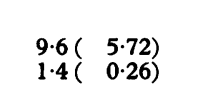 & 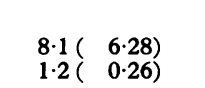 & $\begin{array}{l}0.42 \\
0.18\end{array}$ \\
\hline
\end{tabular}

The $\mathrm{p}$ value reported is for a two tailed $t$ test.

the effect size was multiplied by -1 so that for all variables negative effects correspond to poorer performance by the exposed group relative to the comparison group.

The exposed and comparison groups were similar in all dependent variables; none of the contrasts was statistically significant at $p \leq 0.05$. Trends in the effect sizes appear within clusters of variables. Within the psychophysical variables, which are ordered in fig 3 from the simplest to the most complex, little difference existed between groups in the simpler tasks but the solvent exposed retirees processed stimuli more slowly in the most complex task. An unusual pattern appeared within the group of psychological variables showing effects of different signs for memory and attention. Whereas the exposed group scored higher than the comparison in the verbal memory tasks, they scored lower in attention tasks.

We examined the pattern of memory and attention effects by conducting separate $t$ tests for each component test in the composite variables. The unexpected positive effects for memory appeared consistently across the six short term memory tests. The logical memory task displayed the largest positive effect

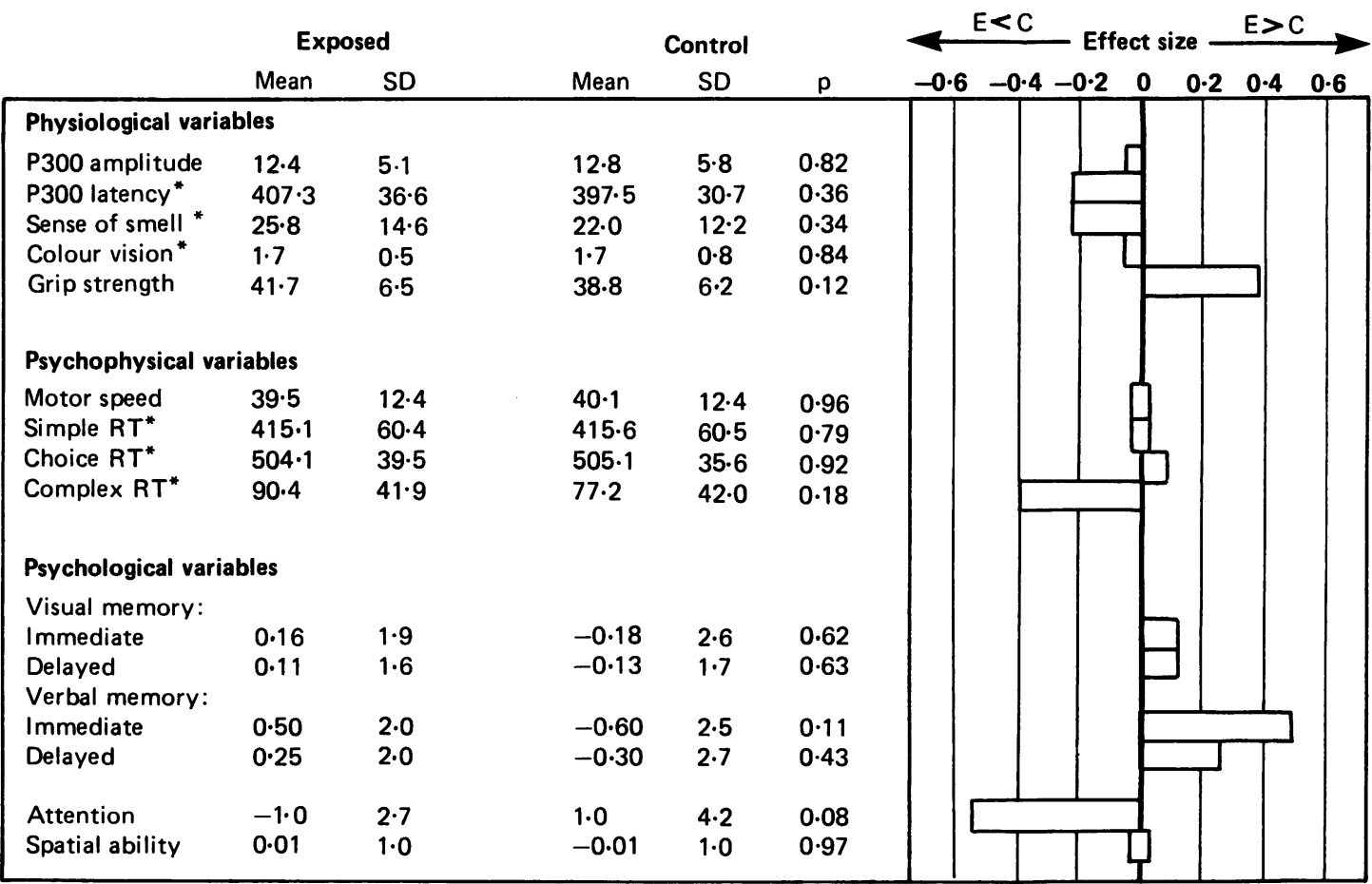

Figure 3 Comparison of exposure groups on three clusters of outcome variables. $p$ Values are for two tailed $t$ tests. One exposed and two control retirees could not provide data for P300 and colour vision, and control for sense of smell, and two exposed and two controls for motor speed. For all other variables, $n=25$ for exposed and 21 for controls.

${ }^{\star}$ Lower scores indicate better performance. The direction of the effect size was changed to adjust for scale. 
(effect size $=0.80 ; p \leq 0.05$ ) whereas the effect sizes associated with the remaining tests ranged from 0.04 to $\mathbf{0} \cdot 25$. In the delayed condition, logical memory again displayed a large effect $(0.65, \mathrm{p} \leq 0.05)$ with two of the four remaining tests having positive effects. By contrast, all of the component variables in the attention composite displayed the hypothesised negative effect, ranging in magnitude from $-0 \cdot 18$ to $-0 \cdot 6$. The largest effect was found with the most complex attention task, the PASAT, and it was significant at $\mathrm{p} \leq 0.05$.

\section{Discussion}

Two cohorts of retired airline mechanics were studied to test the hypothesis that lasting effects on the CNS result from long term exposure to MC. The criteria used to construct the two groups maximised the intergroup difference in previous exposure to $M C$ and minimised current exposure to MC. Non-response and self selection biases that could reduce the generalisation of the research findings were examined. Also, potential confounding variables that were not controlled in the design were measured so that they could be controlled statistically. Analyses of the test results showed that the cohorts did not differ, on average, in any of the primary variables. The two groups were similar in all potential confounding variables and in nearly all outcome measures.

One trend in the data suggested an attention effect worth further investigation. Whereas the solvent exposed group scored higher than the comparison group in memory tests, they scored lower in attention tests. This pattern is interesting because it is unexpected. If no differences existed between groups and all of the observed effect sizes were the result of random measurement and sampling errors, we would expect the magnitude and the sign of the effect size to vary randomly among memory tasks and attention tasks. That was not the case. If the effect sizes for memory were due to a potential confounding variable such as age, education, or verbal intelligence, then we would expect the attention effects to be positive also. The unexpected result suggests that there may be a subtle difference in attention that is difficult to detect.

In a second trend, larger effect sizes were associated with more complex tasks for the reaction time and attention tasks. This trend is consistent with the findings from an experimental study on the effects of exposure to MC on the CNS, ${ }^{6}$ and with the conclusions derived from a review of over 175 studies of low doses of alcohol use. ${ }^{26}$ The most sensitive cognitive tests in those studies were the tests that required subjects to perform two or more tasks simultaneously. In this study, the complex attention task, the PASAT, and the complex reaction time task required subjects to divide their attention between two cognitive tasks, retaining information in short term memory while operating on other information. Future epidemiological studies of subtle CNS effects may benefit from the development and validation of complex tasks appropriate for field research.

The overall conclusion of this study is that no effects on the CNS were attributable to chronic, low level exposure to MC. On the one hand, the findings may be comforting to people who work routinely with MC, particularly as this conclusion was supported by the study conducted by Cherry and her colleagues. ${ }^{8}$ On the other, lack of precision and sampling biases in a study can lead to such a conclusion when, in truth, cohorts differ. When no differences are found, it is important to evalute the bias and precision of the study, and much can be learned for future research by such an examination.

Although several important sources of bias were examined in this study, there may be others. A potential exists for attrition bias-for example, because mechanics who finished work at the airline before they retired were not studied. The direction of attrition bias in this study, if any exists, could be either positive or negative depending on the exposure and health state of the mechanics who left the airline. The finding of no intergroup differences could result, incorrectly, from the disproportionate attrition of healthy, non-exposed workers or unhealthy, impaired, exposed workers. In future retrospective studies it may be beneficial to survey ex-workers to learn their reasons for leaving, their health state, and the attrition rates of each study group.

Random sampling and measurement errors can mask subtle differences between exposed and comparison groups. Although sampling errors may be reduced by increasing sample size, it is not without cost; in most field studies there is a trade off between the size of the sample and the size of the exposure contrast. When an attempt is made to maximise the exposure contrast, as in this study, comparatively small sample sizes are likely to result. It is not possible to maximise the contrast and the sample size simultaneously except in a special unlikely case in which no variability occurs in exposure within the exposed and comparison groups. As long as people in one group experience different degrees of exposure, some will be excluded from study in an extreme groups design. To obtain larger samples within this design would require starting with a much larger parent population. The other alternative, relaxing the criteria for inclusion in the study, would very likely dilute the exposure effect.

If measurement errors reduced precision in the current study, they were most likely to be errors associated with the independent variable, exposure. The dependent variables were measured in standardised conditions by trained examiners who employed established methods. By contrast, retrospective assessments of workplace exposures rely on 
measurements taken for other purposes, sparse data, and assumptions about the stability of exposure levels over time and tasks that may not be valid in all situations. Future retrospective studies may benefit from research into the accuracy of exposure group classifications that are based on employees' work histories and corporations' industrial hygiene records. Retrospective studies may also benefit from the development of biological markers that quantitatively identify remote occupational exposures.

The findings of the current study must be evaluated in context with other examinations of exposure to MC for the purpose of deriving recommendations for workplace practices. Despite the lack of evidence associating $\mathrm{MC}$ to exposure with chronic CNS effects, persons who work with MC should be reminded that exposure has been associated with short term CNS effects, which could contribute to workplace accidents and cardiac arrhythmias.

The authors thank Sarah Thayer for coordinating data collection, Gene Kumekawa for recruiting study participants and monitoring data processing, Bill Birdsong for conducting the substudy of non-response bias, Patricia Quinlan for assisting in the summary of the industrial hygiene data, Gloria Guth and Tom Kelly for conducting the statistical analyses, and Linda Gourley for reviewing an earlier draft of this paper. The research was supported by the National Institute of Environmental Health Sciences by a grant to the University of California.

Requests for reprints to: Andrea A Lash, $\mathrm{PhD}$, Center for Occupational and Environmental Health, Building 30-5th Floor, San Francisco General Medical Center, San Francisco, CA 94110, USA.

1 Rioux JP, Myers RAM. Methylene chloride poisoning: a paradigmatic review. Journal of Emergency Medicine 1988;6:277-38.

2 Rioux JP, Myers RAM. Hyperbaric oxygen for methylene chloride poisoning: Report on two cases. Ann Emerg Med 1989;18:691-5.

3 Tariot PN. Delirium resulting from methylene chloride exposure: Case report. J Clin Psychiatry 1983;44:340-2.

4 Barrowcliff DF, Knell AJ. Cerebral damage due to endogenous chronic carbon monoxide poisoning caused by exposure to methylene chloride. J Soc Occup Med 1979;29:12-4.

5 Shusterman D, Quinlan P, Lowengart R, Cone J. Methylene choride intoxication in a furniture refinisher: A comparison of exposure estimates utilizing workplace air sampling and blood carboxyhemoglobin measurements. $J$ Occup Med 1990;32:451-4.

6 Putz VR, Johnson BL, Setzer JV. A comparative study of the effects of carbon monoxide and methylene chloride on human performance. J Environ Pathol Toxicol 1979;2:97-112.

7 Winneke G. Behavioural effects of methylene chloride and carbon monoxide as assessed by sensory and psychomotor performance. In: Xintaras C, Johnson BL, de Groot I, eds. Behavioural Toxicology: Early detection of occupational hazards. Washington DC: Department of Health, Education and Welfare, National Institute of Occupational Safety and Health. US Government Printing Office, 1974:130-44.

8 Cherry N, Venables H, Waldron HA, Wells GG. Some observations on workers exposed to methylene chloride. Br J Ind Med 1981;38:351-5.

9 Hartman DE. Neuropsychological toxicology: identification and assessment of human neurotoxic syndromes. New York: Pergamon Press, 1988

10 National Institute for Occupational Safety and Health. Organic solvent neurotoxicity. Current Intelligence Bulletin 48, March 31, 1987. London: Department of Health and Social Security 1987. (DHSS Publ No (87-104) 1-36.)

11 Wechsler D. Wechsler adult intelligence scale-revised. New York: The Psychological Corporation, Harcourt Brace Jovanovich, 1981 .

12 Beck AT, Steer RA. Beck depression inventory manual. New York: The Psychological Corporation, Harcourt Brace Jovanovich, 1987

13 Spielberger CD. Stait-trait anxiety questionnaire. Palo Alto: Consulting Psychologist Press, 1983.

14 Amoore JE. PM-Carbinol odor test instruction manual. Richmond, California: Olfacto-Labs, 1987.

15 Mergler D, Blain L. Assessing color vision loss among solventexposed workers. Am J Ind Med 1987;12:195-203.

16 Goodin DS, Aminoff MJ. Electrophysiological differences between subtypes of dementia. Brain 1986;109:1103-13.

17 Baker EL, Letz R, Fidler A. A computer-administered neurobehavioural evaluation system for occupational and environmental epidemiology. J Occup Med 1985;27:206-12.

18 Wechsler D. Wechsler memory scale-revised. New York: The Psychological Corporation, Harcourt Brace Jovanovich, 1987.

19 Buschke H, Fuld PA. Evaluating storage, retention, and retrieval in disordered memory and learning. Neurology 1974;24: 1019-25.

20 Gronwall D. Performance changes during recovery from closed head injury. Proceedings of the Australian Association of Neurologists. 1976, (Vol 13.)

21 Golden CJ. Stroop color and word test. Wood Dale, Illinois: Stoelting Co, 1978. (A manual for clinical and experimental uses. Cat No 30150M.)

22 Reiten RM. Trail making test: manual for administration and scoring. Tucson, Arizona: Reitan Neuropsychology Laboratory, 1986.

23 Ruff RM, Evans RW, Light RH. Automatic detection vs controlled search: A paper-and-pencil approach. Percept Mot Skills 1986;62:504-16.

24 Vandenberg SG, Kuse AR. Mental rotations, a group test of three-dimensional spatial visualization. Percept Mot Skills 1978;47:599-601.

25 Cohen J. Statistical power analysis for the behavioral sciences. Hillside, New Jersey: Lawrence Erlbaum Associates Inc, 1988.

26 Moskowitz H, Robinson CD. Effects of low doses of alcohol on driving-related skills: A review of the evidence. Alexandria, Virginia: SRA Technologies Inc, task one report, July 1987. (Available to the US public through the National Technical Information Service, Springfield, VA 22161.)

Accepted 26 November 1990 